\title{
Botulinum toxin relieves anxiety and depression in patients with hemifacial spasm and blepharospasm
}

This article was published in the following Dove Press journal:

Neuropsychiatric Disease and Treatment

\section{Hongjuan Dong \\ Shanghua Fan \\ Ying Luo \\ Bin Peng}

Department of Neurology, Renmin Hospital of Wuhan University, Wuhan 430060, China
Correspondence: Bin Peng

Department of Neurology, Renmin Hospital of Wuhan University, No. 238, Jiefang Road, Wuhan 430060, China Tel +86278804 I91।

Email binpeng85@I26.com
Objective: To explore the efficacy of botulinum toxin type A (BTX-A) therapy in relieving anxiety and depression in patients with hemifacial spasm (HFS) and benign essential blepharospasm (BEB).

Patients and method: Ninety idiopathic HFS patients and $90 \mathrm{BEB}$ patients were enrolled. The anxiety and depression status were evaluated by self-rating anxiety scale (SAS) and self-rating depression scale (SDS), respectively, before and after the injection of BTX-A.

Results: Before treatment, the SAS and SDS scores of HFS patients were $41.25 \pm 6.35$ and $42.25 \pm 7.57$, respectively. The SAS scores were $40.17 \pm 8.36$ for males and $43.56 \pm 6.10$ for females $(P=0.031)$. The SDS scores were $40.25 \pm 6.46$ for males and $45.48 \pm 7.31$ for females $(P=0.008)$. After treatment, the SAS and SDS scores were $30.12 \pm 4.35$ and $30.58 \pm 4.89$, respectively. There was a significant difference in the SAS and SDS scores before and after treatment. Before treatment, the SAS scores of male and female BEB patients were 56.45 \pm 8.75 and $60.89 \pm 9.11$, respectively, and the SDS scores of male and female BEB patients were 57.90 \pm 7.93 and $60.12 \pm 8.35$, respectively. After treatment, the SAS score was $38.17 \pm 3.67$ and the SDS score was $38.12 \pm 4.15$, with a significant difference in before and after treatment scores.

Conclusion: In HFS and BEB, especially in female patients, there is an association with anxiety and depression. BTX-A can improve the symptoms of anxiety and depression.

Keywords: hemifacial spasm, blepharospasm, anxiety, depression, botulinum toxin type A

\section{Introduction}

In recent years, an increase in cases of hemifacial spasm (HFS) and benign essential blepharospasm (BEB) accompanied by anxiety and depression has been reported. ${ }^{1}$ Tan and Jankovic first reported cases of psychogenic HFS accompanied by depression. ${ }^{2}$ Some patients with HFS and BEB have subjective depressive symptoms when they visit the hospital. Paying attention to the non-motor symptoms in HFS and BEB patients will benefit the patients. Many clinical studies have confirmed that botulinum toxin type A (BTX-A) has significant efficacy and safety in the treatment of HFS and BEB. ${ }^{3}$ However, whether anxiety and depression in HFS and BEB patients could be improved by BTX-A treatment remains unclear. Therefore, in this study, we aimed to explore the efficacy of BTX-A therapy in relieving anxiety and depression in patients with HFS and BEB. We enrolled patients with HFS and BEB, evaluated them using Zung's self-rating anxiety scale (SAS) and self-rating depression scale (SDS), and performed a follow-up assessment.

\section{Patients and method}

\section{Subjects}

This study was approved by the Ethics Committee of Renmin Hospital of Wuhan University and conducted in accordance with the Declaration of Helsinki. All participants 
signed informed consent. HFS and BEB patients who visited the dyskinesia specialist clinic, Department of Neurology, People's Hospital of Wuhan University between April 2014 and October 2014 were enrolled in this study. All patients had to be $18-80$ years of age and voluntarily and actively have participated in the assessment. The patients who did not communicate well or could not complete the survey accurately were excluded. HFS inclusion criteria: clinically diagnosed idiopathic HFS, ${ }^{4}$ usually limited to one side. Exclusion criteria: 1) secondary causes such as facial paralysis, facial nerve injury, and tumors; 2) HFS caused by facial synkinesis, muscle fibrillation, facial tics, and epilepsy; 3) combined with cognitive disorders and mental illness; 4) combined with other diseases of the nervous system; and 5) head computed tomography/magnetic resonance imaging shows brain parenchyma abnormalities. BEB inclusion criteria: the diagnosis met BEB diagnostic criteria ${ }^{5}$ and can be combined with dystonia in adjacent sites. Exclusion criteria: 1) blepharospasm and dystonia of adjacent sites, combined with other neurological symptoms and signs; 2) combined with multiple sclerosis, Parkinson's disease, and other neurological diseases; and 3) secondary blepharospasm. Finally, 90 cases were enrolled as HFS patients and another 90 cases as BEB patients, and they were $31-80$ years old. The average age of HFS patients was $52.34 \pm 9.46$ years, and women accounted for $60 \%$; the average age of BEB patients was $55.12 \pm 10.04$ years, and women accounted for $63.3 \%$.

\section{General data collection}

Detailed medical history was recorded and neurological examination was performed in all 90 HFS cases and 90 BEB cases. Anxiety and depression assessments were performed using Zung's SAS and SDS as described previously. ${ }^{6}$ Total gross SAS score of more than 50 points indicates anxiety symptoms. The higher the score, the more severe the anxiety symptoms. For the SDS scale, 53 points is normal, 53-62 is mild depression, 63-72 is moderate depression, and $>72$ is severe depression.

\section{BTX-A local injection therapy}

BTX-A dry powder (Hengli, Lanzhou Institute of Biological Products, Lanzhou, China) was stored at $-20^{\circ} \mathrm{C}$ and diluted in sterile saline before injection at a concentration of $33 \mathrm{unit} / \mathrm{mL}$. HFS patients were injected according to the distribution of muscle spasms. The dose used for each HFS case was 33-66 units. The main muscles included frontalis, orbicularis oculi, zygomaticus, temporalis, buccinator, masseter muscle, levator labii superioris, and mentalis. In BEB patients, the main muscles involved were the bilateral orbicularis, procerus, frontalis, and corrugator. The dose used for each BEB case was approximately 50-100 units. If the first injection was unsatisfactory, an additional injection was given 1-2 weeks later. Two months after treatment, the SAS and SDS scores were assessed in all patients.

\section{Statistical analyses}

Data were expressed as $\mathrm{x} \pm \mathrm{s}$ and analyzed by SPSS 17.0 software. Group Student's $t$-test was used for comparison between the two groups. Paired $t$-test was used for comparison before and after treatment. The count data were analyzed with the chi-squared test. $P<0.05$ indicated a significant difference.

\section{Results}

As shown in Table 1, the average SAS and SDS scores for female HFS and BEB patients were both significantly higher than those for male patients before treatment. As shown in Table 2, the average SAS and SDS scores were significantly reduced for HFS and BEB patients at 2 months after local injection treatment with BTX-A compared to those for patients before treatment.

\section{Discussion}

Anxiety and depression are important mental health problems and have a significant impact on the morbidity and mortality of disease. ${ }^{7} \mathrm{HFS}$ and BEB patients both have facial spasms, which can cause mental and social anxiety disorders and affect their daily lives and interpersonal communication, and emotional problems can aggravate facial symptoms. ${ }^{8} \mathrm{~A}$ large number of studies have shown that dyskinesias such as Parkinson's disease were accompanied by depression or other mental disorders. ${ }^{9,10}$

The severe motor symptoms of HFS and BEB can cause a change in appearance, social anxiety disorder and mental pain,

Table I Comparison of male and female HFS and BEB patients before treatment $(n=90)$

\begin{tabular}{|l|l|l|l|}
\hline Group & n & SAS score & SDS score \\
\hline HFS group & 36 & $40.17 \pm 8.36$ & $40.25 \pm 6.46$ \\
\hline Male & 54 & $43.56 \pm 6.10^{*}$ & $45.48 \pm 7.31^{*}$ \\
\hline Female & 54 & $56.45 \pm 8.75$ & $57.90 \pm 7.93$ \\
\hline BEB group & 33 & $60.89 \pm 9.11^{*}$ & $60.12 \pm 8.35^{*}$ \\
\hline Male & 57 &
\end{tabular}

Note: $* P<0.05$ vs male (Student's t-test).

Abbreviations: BEB, benign essential blepharospasm; HFS, hemifacial spasm; SAS, self-rating anxiety scale; SDS, self-rating depression scale. 
Table 2 SAS and SDS scores for HFS and BEB patients after BTX-A treatment

\begin{tabular}{|l|l|l|l|l|}
\hline Group & $\begin{array}{l}\text { SAS before } \\
\text { treatment }\end{array}$ & $\begin{array}{l}\text { SDS before } \\
\text { treatment }\end{array}$ & $\begin{array}{l}\text { SAS after } \\
\text { treatment }\end{array}$ & $\begin{array}{l}\text { SDS after } \\
\text { treatment }\end{array}$ \\
\hline HFS & $41.25 \pm 6.35$ & $42.25 \pm 7.57$ & $30.12 \pm 4.35^{*}$ & $30.58 \pm 4.89^{*}$ \\
\hline BEB & $58.90 \pm 10.61$ & $58.78 \pm 9.89$ & $38.17 \pm 3.67^{*}$ & $38.12 \pm 4.15^{*}$ \\
\hline
\end{tabular}

Note: $* P<0.05$ vs before treatment (Student's $t$-test).

Abbreviations: BEB, benign essential blepharospasm; BTX-A, botulinum toxin type A; HFS, hemifacial spasm; SAS, self-rating anxiety scale; SDS, self-rating depression scale.

affect the quality of life and even cause catastrophic traffic accidents. The involuntary closure of the eyelids can cause unclear vision and twitching of the mouth can affect speech, leading to headache, inattention, and irritability in patients. ${ }^{11}$ According to several reports, $30 \%-60 \%$ of BEB patients have anxiety/depression, and $15 \%-30 \%$ of HFS patients have anxiety/depression, both higher than the anxiety/depression rate of the general population. ${ }^{12}$ Our data are consistent with these reports. In addition, for young female patients with HFS and BEB, the changes in their appearance augment anxiety and depression. It has been shown that the severity of depression is related to the severity of HFS. ${ }^{13}$

Previous animal studies have found a correlation between stress-related cortisol level and striatal dopamine level, and anxiety and stress state could lead to adrenocortical insufficiency. ${ }^{14,15}$ In addition, reduced dopamine in the striatum enhances the trigeminal blink reflex, thereby inducing blepharospasm. ${ }^{16}$ It is speculated that human anxiety disorder may lead to a decrease in cortisol secretion, thus resulting in decreased dopamine level in the striatum. ${ }^{17}$ The change in dopamine level is related to blepharospasm.

In this study, we found that more than half of BEB patients had anxiety or depression, and the incidence of anxiety and depression in these patients was significantly higher than those in the HFS group. Although the clinical manifestations of HFS and BEB are similar, BEB involves bilateral eyelids while HFS involves only an unilateral eyelid, and BEB has more impact on the patient's life than HFS causes less distress, and has less impact on daily life. One explanation is that patients have better tolerance for unilateral symptoms (HFS) than bilateral symptoms (BEB). A study in Taiwan showed that blepharospasm could cause transient functional blindness, leading to catastrophic traffic accidents, and untreated BEB patients should avoid riding a motorcycle or driving a car. ${ }^{11}$

Local injection of BTX-A has been used to treat BEB, and it relieves or eliminates the involuntary closure of the eyelids. However, BEB is a chronic disease with recurring symptoms.
We found that in HFS and BEB patients, the average SAS/SDS scores of female patients were greater than those of male patients, consistent with previous studies. ${ }^{18-20}$ In our clinical practice, we observed that female patients were more anxious and more excited than male patients. During the process of injecting BTX, they had more concerns about the condition of the disease. In addition, age at onset for both BEB and HFS is about 50 years. Most of the women are in menopause, and the change in estrogen level may affect female patients. ${ }^{21}$ This may also explain why women have higher anxiety/depression levels than men. Interestingly, recent studies suggest that facial BTX injection can be used to treat depression via the interruption of proprioceptive feedback from the face to the brain that reinforces and maintains the negative emotions that are expressed by the respective mimic muscles. ${ }^{22}$ It is possible that similar effects contribute to antidepressant or anxiolytic effect of BTX in HFS/BSB. However, another recent study reported that BTX treatment of laughter lines was associated with increased depression, reduced emotion recognition ability, and sexual function. ${ }^{23}$ Therefore, further studies are needed to evaluate the efficacy and safety of BTX-A to treat HFS/BSB.

In summary, HFS and BEB have both motor symptoms and non-motor symptoms, affecting the patient's life physically and mentally. BEB patients have more movement disorder, more emotional problems, and poorer quality of life. These findings suggest that we should pay more attention to emotional problems of HFS and BEB patients. BTX-A improved anxiety and depression in these patients while treating the motor symptoms of HFS and BEB. Depression, stress, and anxiety can aggravate the symptoms of HFS and $\mathrm{BEB}$, and early and timely treatment will reduce the incidence of social and occupational dysfunction.

\section{Acknowledgment}

This study was supported by the Fundamental Research Funds for the Central Universities (no 2042017kf0117) and Key Project of Health and Family Planning Commission of Hubei Province (no WJ2015MA007).

\section{Disclosure}

The authors report no conflicts of interest in this work.

\section{References}

1. Tan EK, Lum SY, Fook-Chong S, et al. Behind the facial twitch: depressive symptoms in hemifacial spasm. Parkinsonism Relat Disord. 2005;11(4):241-245.

2. Tan EK, Jankovic J. Psychogenic hemifacial spasm. J Neuropsychiatry Clin Neurosci. 2001;13(3):380-384. 
3. Gill HS, Kraft SP. Long-term efficacy of botulinum a toxin for blepharospasm and hemifacial spasm. Can J Neurol Sci. 2010;37(5):631-636.

4. The Cranial Nerve Disease Center, Shanghai Jiaotong University. Chinese expert consensus on the diagnosis and treatment of HFS. Chin J Minim Invasive Neurosurg. 2014;19(11):528-532.

5. Cummings JL. Depression and Parkinson's disease: a review. Am J Pyschiatry. 1992;149(2):443-454.

6. Wang XD, Wang XL, Ma H. Mental Health Assessment Scale Manual. Chinese Mental Health Journal Press: Beijing; 1999:194-197, 235-238.

7. Kolar D. Addictive potential of novel treatments for refractory depression and anxiety. Neuropsychiatr Dis Treat. 2018;14:1513-1519.

8. Tan EK, Fook-Chong S, Lum SY, Lim E. Botulinum toxin improves quality of life in hemifacial spasm: validation of a questionnaire (HFS-30). J Neurol Sci. 2004;219(1-2):151-155.

9. Burn DJ. Beyond the iron mask: towards better recognition and treatment of depression associated with Parkinson's disease. Mov Disord. 2002;17(3):445-454.

10. Cummings JL. Depression and Parkinson's disease: a review. Am J Pyschiatry. 1992;149(2):443-454.

11. Streitová H, Bareš M. Long-term therapy of benign essential blepharospasm and facial hemispasm with botulinum toxin A: retrospective assessment of the clinical and quality of life impact in patients treated for more than 15 years. Acta Neurol Belg. 2014;114(4):285-291.

12. Setthawatcharawanich S, Sathirapanya P, Limapichat K, Phabphal K, Lim I. Factors associated with quality of life in hemifacial spasm and blepharospasm during long-term treatment with botulinum toxin. Qual Life Res. 2011;20(9):1519-1523.

13. Hall TA, McGwin G, Searcey K, et al. Health-related quality of life and psychosocial characteristics of patients with benign essential blepharospasm. Arch Ophthalmol. 2006;124(1):116-119.
14. Sohn YH, Voller B, Dimyan M, et al. Cortical control of voluntary blinking: a transcranial magnetic stimulation study. Clin Neurophysiol. 2004;115(2):341-347.

15. Hanakawa T, Dimyan MA, Hallett M. The representation of blinking movement in cingulate motor areas: a functional magnetic resonance imaging study. Cereb Cortex. 2008;18(4):930-937.

16. Esmaeli-Gutstein B, Nahmias C, Thompson M, Kazdan M, Harvey J. Positron emission tomography in patients with benign essential blepharospasm. Ophthalmic Plast Reconstr Surg. 1999;15(1):23-27.

17. Hutchinson M, Nakamura T, Moeller JR, et al. The metabolic topography of essential blepharospasm: a focal dystonia with general implications. Neurology. 2000;55(5):673-677.

18. Barahona-Corrêa B, Bugalho P, Guimarães J, Xavier M. Obsessivecompulsive symptoms in primary focal dystonia: a controlled study. Mov Disord. 2011;26(12):2274-2278.

19. Munhoz RP, Teive HA, Della Coletta MV, et al. Frequency of obsessive and compulsive symptoms in patients with blepharospasm and hemifacial spasm. Arq Neuropsiquiatr. 2005;63(2A):213-216.

20. Biuk D, Karin AA, Matić S, Barać J, Benasić T, Stiglmayer N. Quality of life in patients with blepharospasm. Coll Antropol. 2013;37(1):29-33.

21. Eman AM, Mahmoud ME. Effect of aerobic exercises versus foot reflexology on post-menopausal depression. Clin Exp Obstet Gynecol. 2017;44(5):726-729.

22. Wollmer MA, Neumann I, Magid M, Kruger TH. Shrink that frown! Botulinum toxin therapy is lifting the face of psychiatry. G Ital Dermatol Venereol. 2018;153(4):540-548.

23. Lewis MB. The interactions between botulinum-toxin-based facial treatments and embodied emotions. Sci Rep. 2018;8(1):14720.
Neuropsychiatric Disease and Treatment

\section{Publish your work in this journal}

Neuropsychiatric Disease and Treatment is an international, peerreviewed journal of clinical therapeutics and pharmacology focusing on concise rapid reporting of clinical or pre-clinical studies on a range of neuropsychiatric and neurological disorders. This journal is indexed on PubMed Central, the 'PsycINFO' database and CAS,

\section{Dovepress}

and is the official journal of The International Neuropsychiatric Association (INA). The manuscript management system is completely online and includes a very quick and fair peer-review system, which is all easy to use. Visit http://www.dovepress.com/testimonials.php to read real quotes from published authors. 